\title{
APLICAÇÃO DOS CONCEITOS DE REDES INTERORGANIZACIONAIS NO SETOR VAREJISTA: UMA PROPOSTA DE APLICAÇÃO DOS CONCEITOS DE BROKERS E OPERADORES LOGÍSTICOS EM EMPRESAS DISTRIBUIDORAS DE ALIMENTOS \\ APPLICATION OF INTERFIRM NETWORKS CONCEPTS IN THE RETAIL SECTION: AN APPLICATION OF THE BROKER CONCEPTS AND OPERATORS LOGISTICS IN DISTRIBUTING COMPANIES OF FOODS
}

\author{
Gesinaldo Ataíde Cândido \\ Professor Titular \\ Universidade Federal de Campina Grande \\ Unidade Acadêmica de Administração e Contabilidade \\ Avenida Aprígio Veloso, 882, Bodocongó, Campina Grande, CEP: 58000-000 \\ (83) 33101217 / gacandido@uol.com.br
}

Leandro Maurício Medeiros Vieira

Professor

Universidade Federal do Rio Grande do Sul

Escola de Administração

Rua Washington Luis, 855, Porto Alegre, CEP: 90010-460

(51) 33163536 / administradores@ administradores.com.br 


\title{
RESUMO
}

Uma das principais práticas adotadas pelas organizações no atual ambiente de negócios e de gestão tem sido a aplicação dos princípios de redes, baseado nos conceitos da parceria, da associação e da cooperação. As experiências desse novo tipo de práticas organizacionais têm sido bem sucedidas em diversos setores econômicos, criando melhores condições para a obtenção de vantagens competitivas. Neste trabalho, é feito um estudo para verificação da possibilidade de aplicação desses conceitos varejista, dentro das novas perspectivas do gerenciamento de suprimentos e da logística. Neste sentido, o trabalho faz um diagnóstico do setor varejista, verificando as possibilidades da aplicação dos princípios de redes numa empresa atuante junto ao setor de representação e distribuição de alimentos, a partir de um processo de mudança estratégica, propondo um modelo organizacional baseado nos conceitos de brokers e operador logístico, os quais substituem e / ou incorporam os diversos agentes envolvidos com a distribuição de alimentos, quais sejam: o representante comercial, o distribuidor e o atacadista.

Palavras-chaves: competitividade, redes organizacionais, cadeia de suprimentos.

\begin{abstract}
One of main the practical ones adopted for the organizations in the current environment business-oriented and of management has been the application of the principles of nets, based in the concepts of the partnership, the association and the co-operation. The experiences of this new type of practical of management have been successful in diverse economic sectors, creating better conditions for the attainment of competitive advantages. In this work, a study is made to see the possibility of application in the sector of food distribution, inside of the new perspectives of the supply management and the logistic one. In this direction, the work makes a diagnosis of the retail sector, verifying the possibilities of the application of the principles of nets in a together operating company to the representation sector and food distribution, from a process of strategic change, considering a management model based in the concepts of brokers and logistic operator, which they substitute and/or they incorporate the diverse involved agents with the food distribution, which are: the commercial representative, the deliverer and the wholesaler.
\end{abstract}

Key words: competitiveness, network organizational, chain of supply.

\section{INTRODUÇÃO}

O interesse pelo tema organizações em redes surgiu em função das características do atual ambiente de negócios e de gestão, as quais envolvem uma intensa concorrência resultante da globalização, do avanço tecnológico, da mudança no comportamento do consumidor, entre outros fatores. Isto forçou as empresas a buscarem melhorias contínuas de desempenho; diminuição do ciclo de vida dos seus produtos e serviços; maior variedade na oferta de produtos e serviços e, políticas de redução de custos. Uma estratégia para sobrevivência e desenvolvimento empresarial tem sido, ao invés de inúmeros empresários 
concorrendo entre si - cada um com sua forma de gestão e organização - as empresas executarem apenas as funções nas quais são melhores, deixando para terceiros as outras funções em que estes são melhores. Surge então, um conjunto de empresas independentes que mantêm relações dinâmicas e bem específicas. Esta nova forma de atuação empresarial é pautada na aplicação dos princípios de redes sociais, envolvendo a prática da associação, a parceria, a ajuda mútua, a complementaridade, etc.

As experiências desse novo tipo de organização têm sido bem sucedidas em diversos setores e segmentos econômicos, criando melhores condições para a obtenção de vantagens competitivas significativas e permanentes. No setor de distribuição de alimentos, as experiências na aplicação dos princípios de redes são ainda incipientes, dadas às próprias características do setor pautada num clima de desconfiança entre os diversos elos da sua cadeia produtiva e as possibilidades de que vários integrantes desta cadeia estarem realizando as mesmas atividades e atuando em mercados comuns.

A evolução na forma de agir das organizações que atuam no setor de distribuição de alimentos, no que se refere à aplicação dos princípios de redes, propiciou o surgimento de novos formatos e arquiteturas organizacionais, com destaque para: o broker e o operador logístico. Em linhas gerais, a figura do broker e do operador logístico significam, para a indústria, uma forma de aumentar a sua participação nos pequenos pontos de venda; para os clientes, uma maneira de receber atendimento personalizado e preços competitivos e; para os atacadistas e distribuidores, novas oportunidades de negócios.

A partir destas considerações iniciais, surge o seguinte problema: como a aplicação dos princípios de redes pode contribuir para a melhoria das inter-relações entre as empresas envolvidas com a distribuição de alimentos? Para a realização do trabalho foi realizada uma pesquisa junto a uma empresa representante de vários fabricantes de produtos alimentícios localizados na região Sul, com atuação em todos os Estados do Nordeste brasileiro. Neste sentido, o objetivo do trabalho foi realizar estudos prospectivos para propor a uma empresa distribuidora de alimentos uma nova forma de atuação, quais sejam: operador logístico e broker, aplicando os conceitos de redes interorganizacionais nos níveis de distribuição e comercialização da cadeia produtiva do setor de alimentos.

Para a obtenção de resposta para o problema formulado e a consecução do objetivo proposto para este trabalho, o mesmo está assim estruturado: caracterização do atual ambiente de negócios e de gestão, especificamente o segmento e setor econômico envolvido 
com a distribuição de alimentos; demonstração de como a aplicação dos princípios de redes (broker e operador logístico) no setor de distribuição de alimentos constitui-se numa estratégia capaz de tornar as empresas envolvidas mais competitivas; mostrar como a aplicação dos princípios de redes pode ser implementada, a partir de um estudo de caso realizado, no qual são explicitadas as atuais formas de funcionamento da empresa e em seguida, além disso, são propostas novas formas de atuação, capazes de tornar a empresa mais competitiva.

\section{REFERENCIAL TEÓRICO}

\subsection{Caracterização do Atual Ambiente de Negócios e as Novas Formas de Gestão Organizacional}

Nos últimos anos, o ambiente de negócios tem se caracterizado por um crescente aumento das pressões sobre as organizações, devido a um conjunto de mudanças políticas, econômicas e sociais que dificultam cada vez mais a obtenção das devidas condições de sobrevivência e desenvolvimento das empresas. Nadler \& Tushman (1994) apontam um conjunto de forças que contribuíram para aumentar a pressão sobre as organizações, dentre elas: um número crescente de competidores eficientes está surgindo nos diversos segmentos da economia; a capacidade de ofertar a maioria dos produtos e serviços é superior à demanda; a competição ocorre hoje em escala global; clientes que exigem maior valor, qualidade e menores preços nos produtos e/ou serviços; etc.

Em conseqüência direta das influências deste conjunto de forças e do processo de mudanças no ambiente organizacional, houve um aumento da incerteza e da insegurança dentro das organizações, tornando-se necessária à adoção de um conjunto de mecanismos e instrumentos capazes de criar e manter a eficiência, eficácia e efetividade. Logo, as organizações têm buscado permanentemente se adaptar, reestruturarem-se, flexibilizaremse, procurando sempre formas de inovação dentro das novas configurações do ambiente.

Cândido (2001) aponta que, dada as atuais características do ambiente organizacional, torna-se urgente para as organizações à busca de mecanismos para tornarem-se mais competitivas, num contexto de permanente instabilidade, de pressões dos concorrentes, clientes, fornecedores, agentes regulamentares, etc. Para o autor, a maior parte das organizações adota uma estrutura e conjunto de práticas gerenciais que foram criados para funcionar num ambiente mais estável e previsível. As empresas que poderão 
obter as devidas condições para sobrevivência e desenvolvimento serão aquelas que tenham ou venham a ter a capacidade de reagir às implicações das mudanças, antevê-las e desenvolver antecipadamente as suas estratégias. Para isso, é necessária a criação de novas ferramentas e mecanismos que dêem suporte às novas práticas organizacionais, dentre elas destacam-se as redes interorganizacionais, dentro do princípio da core competence proposto por Hamel \& Prahalad (1994), no qual todas as empresas têm competências essenciais, e devem concentrar-se nessas para obter vantagens e diferenciais competitivos.

Em geral, as organizações não possuem o conjunto de todas as competências necessárias para tirar proveito das oportunidades que surgem no mercado. Conseqüentemente, a necessidade de reunir recursos e competências tem forçado as empresas a formar alianças cooperativas, o que acarreta em mudanças na estratégia das organizações, que podem assumir uma variedade de formas, dentre elas a atuação em redes, que tem sido efetivamente adotada como resposta estratégica às pressões ambientais sofridas pelas organizações.

\subsection{Os Conceitos e as Formas de Aplicação dos Princípios de Redes Inter-}

\section{Organizacionais}

A organização em rede representa uma nova forma de atuação empresarial, a qual implica mudanças nas formas de inter-relacionamento entre as empresas e destas com o mercado. Nestas contingências, ocorre uma redefinição dos antigos princípios das estruturas burocráticas e da hierarquia inflexível, pela necessidade premente de vinculação entre os processos referentes à coordenação da atividade econômica.

Achrol \& Kotler (1999) definem a organização em rede como um mecanismo de mercado para alocar pessoas e recursos para problemas e projetos de maneira descentralizada, buscando sempre a flexibilidade e adaptabilidade às mudanças. $\mathrm{O}$ seu foco de atuação é centrado na integração entre a estrutura formal e as múltiplas formas de relacionamentos sociais vigentes numa organização. Nohria (1992) aponta que a maioria dos autores dentro da "teoria de redes" considera que todas as organizações se situam em redes sociais, e devem ser entendidas e analisadas em termos de redes múltiplas de relações internas e externas.

Cândido (op. cit.) define uma rede organizacional como uma estrutura organizacional na qual podem participar empresas que devido a limitações de ordem 
dimensional, estrutural e financeira, não podem assegurar as devidas condições de sobrevivência e desenvolvimento. Possui uma estrutura celular não rigorosa, composta de atividades que agregam valor e introduzem novos materiais e elementos, constantemente.

\subsection{A Aplicação dos Princípios de Redes no Setor Varejista Através do} Gerenciamento da Cadeia de Suprimentos

Um modelo básico de cadeia de suprimento no setor varejista envolve relações que vão desde o fornecedor de matéria-prima e insumos até o consumidor final, passando pelo fabricante, distribuição e varejistas, conforme figura abaixo:

Figura 1: Modelo básico de rede suprimentos

\section{Fornecedores \\ Fabricante \\ Distribuição \\ Varejista \\ Consumidor}

Poirier \& Reiter (1997) apresentam um modelo mais elaborado, representado na figura 2 onde estão incluídos os fornecedores dos fornecedores para mostrar a ligação completa dos grupos empresariais que se unem para adquirir, transformar e distribuir produtos e serviços para os consumidores.

Figura 2. Modelo de Cadeia de Suprimento de Kearney

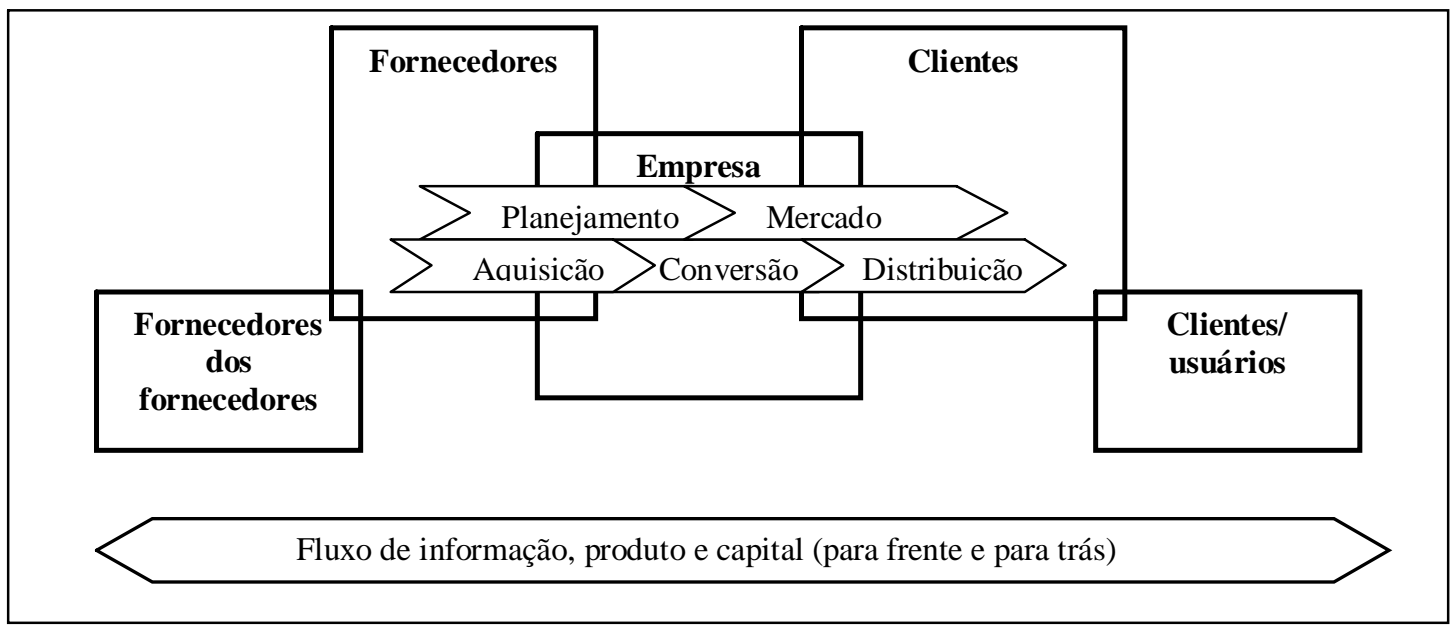

Fonte: adaptado de Kearney apud Poirier \& Reiter (1997)

No esforço para reduzir os custos da cadeia de suprimento e melhorar sua eficiência, muitas organizações têm adotado uma estratégia única, padrão, para os serviços de logística 
oferecidos. Porém, deve-se considerar que os clientes são de tipo e porte variados e têm, portanto, necessidades diferentes. Miller \& Torres (2000) relatam que, tradicionalmente, as pessoas atribuem à logística uma função limitada, como as atividades que envolvem o armazenamento e a entrega dos produtos. Embora associadas a um alto investimento, essas atividades não são particularmente difíceis de se executar.

Os autores alertam que existe uma tendência em simplificar ao máximo as operações de logística utilizando um nível único e padronizado de serviço para todos os clientes, chegando até a desestimular, ou ignorar, necessidades específicas de um cliente. Considerando, ainda, que o fornecimento de serviços de logística representa uma área ampla e inexplorada para a criação de valor agregado mais alto nas transações de compra. Quando compram, os clientes adquirem muito mais que simplesmente o produto, adquirem o pacote de serviços que acompanha o produto, que inclui componentes como flexibilidade de preço, promoções, acordos e descontos, crédito e condições de pagamento, apoio de merchandising, serviço de pós-venda e pós-entrega e serviços de logística.

La Conde (2000) afirma que as cadeias de suprimento atuais tendem a ser múltiplas e integradas. Neste sentido, o gerenciamento da cadeia de suprimentos está cada vez mais complexo em função dos mercados exigirem sistemas logísticos capazes de manejar uma variedade maior de produtos em áreas geográficas muito mais extensas.

A importância de se ter maior integração entre cada elemento da cadeia, e a logística é fundamental para um melhor gerenciamento da cadeia de suprimentos. Cada elo da cadeia - compras, produção, estoque, distribuição, vendas e serviços ao cliente - têm impacto simultâneo sobre os outros elos, e é essencial compreender o alcance desse impacto. Com uma abordagem integrada de cada elo da cadeia de suprimentos e do sistema logístico, as organizações passarão a obter significativas vantagens competitivas por meio do aumento dos níveis de serviço ao cliente e da redução de estoques e custos de armazenamento.

\subsection{A indústria brasileira de alimentos e a necessidade de mudança na forma de atuação empresarial}

Nos anos 90, a indústria brasileira de alimentos passou por grandes mudanças, produzida principalmente por dois fatores: a abertura às importações e a estabilização monetária. Riveras \& Mathias (1998) analisam as consequiências desses dois fatores, e 
concluem que, com a liberalização das importações, uma gama variada de novos produtos passou a ser oferecida aos consumidores, num movimento que estimulou a concorrência doméstica; o aumento do poder aquisitivo da população, por sua vez, com a estabilidade monetária, contribuiu para ampliar o mercado.

Coutinho \& Ferraz (1994), ao estudarem a competitividade de indústria brasileira de alimentos, apontam que uma das suas principais características é o direcionamento para o mercado doméstico. As empresas, inclusive as de maior capacitação, tendem a encarar o mercado externo apenas como alternativa de escoamento da produção em fases de maior retração da demanda interna. Os autores apontam que, em virtude do baixo poder aquisitivo da população, para grande parte dos consumidores brasileiros, o preço seja o atributo mais importante do produto, priorizado mesmo em detrimento da qualidade. $\mathrm{O}$ reduzido poder de compra leva à aceitação de produtos de baixa qualidade, em alguns casos até mesmo impróprios para o consumo.

Apesar disso, a indústria alimentícia brasileira tem presença significativa no mercado externo em produtos específicos, a partir de empresas de padrão internacional. No setor de abate, por exemplo, três empresas são responsáveis por mais de $70 \%$ das exportações de aves e têm evoluído consistentemente para a maior agregações de valor na sua pauta de produção, tanto para o mercado interno como externo. As maiores empresas do setor têm alcançado elevados níveis de produtividade e têm tido o mesmo acesso à tecnologia de processo e aos "pacotes genéticos" das empresas líderes mundiais. Mesmo em áreas em que as perspectivas de avanço da fronteira tecnológica são mais fortes, estas empresas estão bem posicionadas.

\subsection{Conceitos e formas de aplicações dos conceitos de redes para empresas distribuidoras de alimentos: o operador logístico e o broker}

Num ambiente organizacional que enfatiza velocidade e flexibilidade, combinações inteligentes de novas formas de relacionamentos possibilitam a obtenção de melhores condições de desenvolvimento. No caso das redes empresariais essa condição é obtida na medida em que, as empresas integrantes passam a atuar em novos setores e nichos de mercado, passam a compartilhar custos e conhecimentos em áreas que tradicionalmente podem ser custeadas apenas por empresas de grande porte, maior acesso a know-how e 
informações através de novas relações de colaboração. Isto pode ser obtido sem que as empresas integrantes da rede tenham de abrir mão de sua autonomia e independência.

A aplicação dos princípios de redes pode contribuir para a melhoria das interrelações das empresas envolvidas com a distribuição de alimentos, ajudando-as a conquistar verdadeiras vantagens competitivas. $\mathrm{O}$ atual ambiente de negócios, caracterizado pela acirrada concorrência, pela busca da redução de custos, e pela premissa de atender de forma mais eficiente os pontos finais da cadeia produtiva, tem forçado as empresas dos mais diferentes segmentos a rever os seus conceitos de operação.

Esse movimento tem influência direta no setor atacadista, onde os diversos agentes envolvidos precisam firmar parcerias mais sólidas com os membros da sua cadeia produtiva, agregando valor aos produtos que comercializa. Em função deste contexto e contingências, duas fortes modalidades de serviços podem servir como alternativas para a aplicação dos princípios de redes no setor de distribuição de alimentos: os brokers e os operadores logísticos. Ambos podem proporcionar vantagens consideráveis, tanto na redução de custos na cadeia de abastecimento quanto em eficiência, agilidade, e otimização de recursos para fabricantes, varejistas e consumidores.

As modalidades mais tradicionais de atuação das empresas no setor de distribuição de alimentos envolvem as funções do atacadista e do distribuidor, discriminadas conforme quadro abaixo:

Quadro 1: Discriminação das funções dos agentes tradicionais responsáveis pela distribuição de alimentos

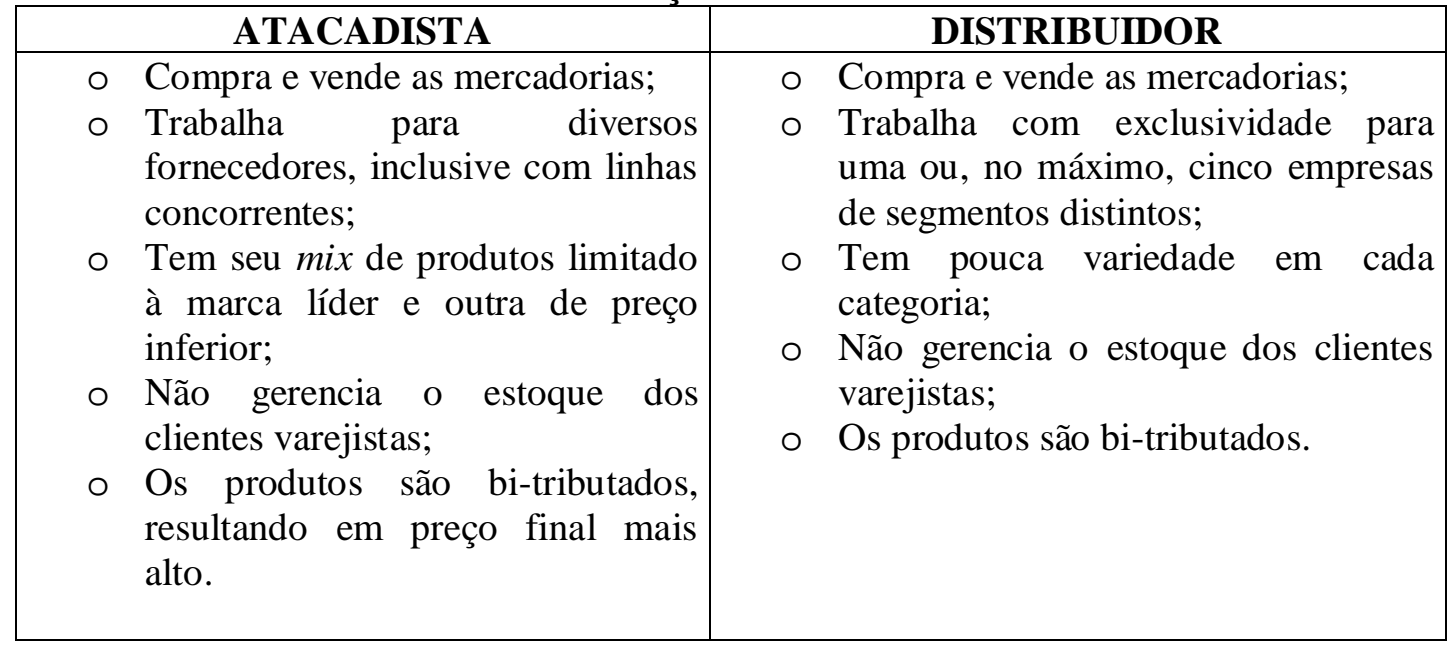

Fonte: Adaptado de Salgado \& Santos (2002) e Ferreira (2002) 
Seguindo a tendência de dedicar-se mais ao seu core-business no sentido de atuar em um mercado cada vez mais competitivo, os serviços de distribuição, armazenagem, controle e administração de estoques começaram a ser terceirizado pela indústria. Neste sentido, surge uma evolução na forma de atuação destes tipos de agentes que caracterizam a aplicação dos princípios de redes em parte da cadeia produtiva na indústria de alimentos, envolvendo uma nova forma de atuação, com funções diferenciadas dos antigos atacadistas e distribuidores. São eles, o operador logístico e o broker, com novas e diferenciadas funções, conforme discriminado em quadro abaixo:

\section{Quadro 2: Discriminação das funções dos agentes contemporâneos responsáveis pela} distribuição de alimentos

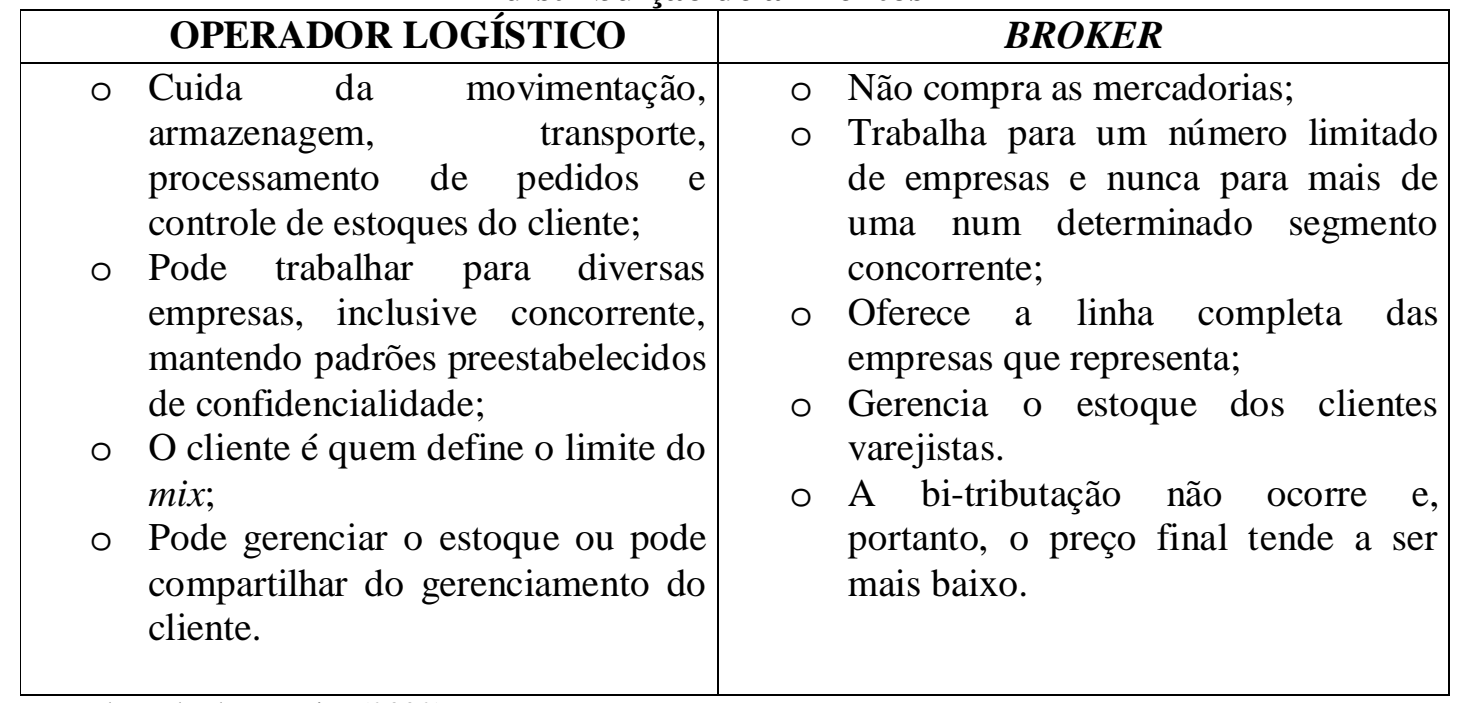

Fonte: adaptado de Ferreira (2002)

O operador logístico é uma empresa contratada pelo fabricante para cuidar da movimentação, armazenagem, transporte, controle de estoques e abastecimento, substituindo as indústrias em etapas importantes da sua gestão de cadeia de suprimentos. Africk \& Calkins (1994) definem operador logístico como sendo uma empresa terceirizada que desempenha parte ou todas as funções logísticas de uma empresa, ressaltando que os serviços físicos oferecidos são mais customizados e mais complexos, envolvendo um amplo número de funções, contratos de longo prazo e relacionamentos mútuos benéficos.

Esta nova forma de convivência dos fabricantes com os varejistas têm se constituído numa oportunidade dos fabricantes diminuírem seus custos e melhorarem a qualidade da sua pós-venda e, para os varejistas uma possibilidade de crescimento, na 
medida em que novas atribuições lhe serão conferidas. Tudo isto pode propiciar vantagens para todos os integrantes da cadeia produtiva do setor varejista.

Por outro lado, o broker é uma empresa prestadora de serviços de vendas, promoção, merchandising, pesquisa de mercado e ações de ponto-de-venda. Seu papel difere em muito da função do representante comercial, pois agrega mais serviços à atividade de vendas. Por parte da indústria, consiste-se numa grande oportunidade de não ter a comercialização final de seus produtos concentrada na mão de poucas e grandes cadeias de supermercado.

Na prática, o broker é uma empresa contratada pelo fabricante para cuidar das vendas, promoção, merchandising, pesquisa, crédito e cobrança nas lojas do pequeno e médio varejo. Para a indústria, é uma forma de aumentar a sua participação nos pequenos pontos de venda. Para os clientes, uma maneira de receber atendimento personalizado e preços competitivos. E, para os atacadistas e distribuidores, novas oportunidades de negócios. O broker trabalha para um número limitado de fabricantes, ofertando seus produtos no varejo e aplicando práticas de merchandising, entre outras funções. Uma de suas principais características - e real vantagem competitiva - é que o faturamento ao varejo, através dos serviços de um broker, é feito diretamente em nome da indústria, ou seja, elimina-se uma etapa de incidência dos impostos em cascata, na medida em que se trata de uma opção para a indústria dirigir-se diretamente ao pequeno varejo sem passar pelo distribuidor, evitando-se a bi-tributação.

O broker, por ser um agente de vendas e de marketing que atua como uma extensão da indústria, pode abastecer não só o pequeno varejo, mas também, as grandes redes de supermercados. Em relação ao varejo, o broker representa uma excelente oportunidade para se obter melhor condição em relação a preço, e também orientação especializada acerca de mix, merchandising e marketing, contribuindo para torná-los mais competitivos frente às grandes redes. Ao contrário do atacadista e do distribuidor, que normalmente trabalham apenas com as marcas de maior giro, o broker disponibiliza todo o leque de produtos da indústria que representa. Na maior parte dos casos, a indústria consegue, com a ajuda do broker, aumentar em mais de $50 \%$ as suas vendas nas praças onde o agente atua.

O processo de implantação do broker possui algumas peculiaridades. Duas áreas precisam ser bem equacionadas no relacionamento indústrias e broker, são elas: o fluxo de 
informações e a qualificação do pessoal que trabalha nos brokers. É necessário pessoal na linha de frente que não apenas desenvolvam as vendas, mas que conheçam as diversas formas de atuação e funcionamento da empresa.

Indubitavelmente, o broker representa o futuro do setor de distribuição. Porém, esse agente só poderá ser viabilizado se um operador logístico transportar a mercadoria da indústria até a loja. Para otimizar ainda mais esse processo, uma mesma empresa pode optar por unir essas duas funções, agindo como broker e operador logístico simultaneamente.

Os conceitos de operador logístico e broker ainda não foram totalmente assimilados no mercado Brasileiro, pois sua atividade ainda é incipiente, quando comparado com países mais desenvolvidos. Um dos fatores que dificulta sua implantação é que a mudança da atividade comercial para a de prestador de serviço inibe a realização de serviços logísticos pelos atacadistas. Apesar disso, essas novas formas de atuação do setor varejista têm apresentado índices de crescimento nos últimos anos.

\section{Aspectos Metodológicos}

Dada às características do problema de pesquisa e dos objetivos formulados, o trabalho constitui-se num estudo exploratório e descritivo, realizado através de um e estudo de caso, o qual para Yin (2001) deve ser utilizado quando a forma da questão de pesquisa é do tipo como ou por que, além disso, a pesquisa não exige controle sobre eventos e focaliza acontecimentos contemporâneos. No estudo de caso realizado, caracterizado como de caráter exploratório e descritivo, é feita uma proposta para viabilização de um tipo de rede para um determinado segmento e setor econômico.

Quanto às técnicas para a coleta de dados foi utilizada a documentação indireta, através de consultas a livros, artigos de revistas e periódicos, sites na internet que envolvesse os temas tratados na pesquisa e, técnicas de documentação direta do tipo intensiva, adotando os seguintes procedimentos: 1) análises documentais, procurando conhecer as diversas formas de comunicação impressa na organização; 2) utilização da observação não-participante, com o objetivo de conhecer a realidade, a estrutura e funcionamento de empresas envolvidas com a distribuição e comercialização de alimentos em determinada localidade e contexto e 3) aplicação de entrevistas semi-estruturada, a partir da elaboração de um roteiro pré-definido a partir do conteúdo da fundamentação 
teórica do trabalho, assim como as inferências dos pesquisadores obtidas através da observação não participante.

Para a obtenção dos dados referentes á aplicação das técnicas de documentação direta foram utilizados os seguintes instrumentos de pesquisa: 1) roteiro pré-definido para se fazer à caracterização da empresa pesquisada, especialmente nos aspectos relacionados à formulação e/ou adaptação das estratégias empresariais vigentes e 2) roteiro para entrevista semi-estruturada realizada com proprietário e executivos da empresa.

O tratamento das informações colhidas foi realizado a partir da análise do grau de confiabilidade, o qual foi obtido através de informações obtidas junto ao estabelecido na fundamentação teórica do trabalho; nos comentários e sugestões propostas em conversas paralelas com pesquisadores no tema e empresários envolvidos com o setor de distribuição e comercialização de alimentos e, finalmente, com a percepção dos pesquisadores decorrente das suas observações e inferências com a condução das diversas fases da pesquisa.

\section{Apresentação e Análise dos Dados}

Para a realização deste trabalho, tomou-se como objeto da pesquisa uma empresa que atua no setor de distribuição e representação de fabricantes de produtos alimentícios da região Sul, tendo seu campo de atuação centrado na região Nordeste. Os tipos de produtos alimentícios que a empresa representa e distribui são, basicamente: carnes, peixes, aves, laticínios e embutidos em geral. Sua carteira de clientes é composta, basicamente, de grandes e médios distribuidores atacadistas.

A empresa é do tipo familiar, constituída por uma sociedade de responsabilidade limitada, tendo iniciado suas atividades no início da década de 90, como representante de um único fornecedor. Na medida em que, a empresa foi tornando conhecida a marca que representava, novos clientes passaram a ser incorporados à sua carteira, incluindo grandes distribuidores e redes de supermercado.

Em relação ao seu ambiente interno, a empresa adota práticas que procura agregar valores de parceria e participação. Não existem barreiras entre os níveis hierárquicos e o clima organizacional pode ser caracterizado como harmonioso, de companheirismo e de boas relações entre os proprietários e seus empregados. A sua estrutura organizacional é enxuta e flexível, com pessoal qualificado, de habilidades múltiplas. A empresa conta com 
uma estrutura informacional composta por modernos computadores interligados em rede. O Sistema de Informação Gerencial utilizado pela organização foi desenvolvido dentro da própria companhia e visa controlar o seu processo básico de trabalho (formação de pedidos e cargas), além de fornecer informações para todos os componentes da sua cadeia produtiva.

A sua área de atuação pode ser caracterizada como um mercado que tem um grande potencial de crescimento, uma vez que, a região Nordeste desponta como o novo pólo consumidor do Brasil em função dos seus índices de crescimento econômico e a possibilidade de melhorias no poder aquisitivo da população, o que necessariamente leva ao consumo de novos tipos de produtos.

Uma descrição do seu ambiente externo pode ser realizada a partir da definição dos seus Stakeholders, os quais envolvem: fornecedores, clientes; transportadores e concorrentes. A variável do seu ambiente externo que caberia maior atenção refere-se aos seus concorrentes. Existem dois tipos básicos de concorrentes e é essencial diferenciá-los, de forma a possibilitar as melhores condições de convivência e para adequar as estratégias quando necessário. Os concorrentes são do tipo: 1) Representantes de produtos similares Empresas de representação de outros fornecedores, que representam produtos similares e atuam na mesma região e 2) Produtos similares sem representantes - algumas empresas de porte maior vendem diretamente seus produtos aos distribuidores/supermercados, sem a intermediação de representantes, com um tipo de venda diferenciada.

Os dados coletados permitem inferir que, apesar das boas relações existentes, as expectativas dos concorrentes em relação à empresa sejam a de penetrar nos mercados de domínio dessa empresa, tomar espaços conquistados por ela, superar e antever suas ações, etc. A rivalidade entre os concorrentes assume corriqueiramente a forma de disputa por posição. As táticas usadas aqui variam de concorrência de preços, batalhas de publicidade, enfoque nos serviços prestados e vantagens aos clientes, entre outras.

Uma coalizão, nesse caso, representaria uma forte ameaça, uma vez que o "novo" concorrente poderia obter produtos com custo menor, aumentar o seu poder de negociação, abranger maiores fatias de mercado ou conquistar alguma forma de liderança. Vale lembrar que a aquisição de uma empresa já existente, ou um processo de fusão com a intenção de construir uma posição no mercado, deve ser visto como entrada, mesmo que nenhuma entidade inteiramente nova tenha sido criada. Ainda: a entrada de um novo concorrente 
sempre traz consigo o desejo de ganhar parcela de mercado e freqüentemente recursos substanciais.

Pode-se identificar que existe uma série de fatores de ordem econômico-políticosocial que afetam e exercem influência direta nas atividades da empresa, dentre eles: 1) eventuais desvalorizações do Real implicam em aumento de preços, os quais, muitas vezes, os clientes da empresa não estão dispostos a incorporar. Estas desvalorizações ocorrem basicamente, pelo fato da maioria dos fornecedores utilizar matéria-prima (como ração, por exemplo) comprada em dólar. Um aumento dessa moeda acarreta aumento no preço final do produto; 2) pacotes econômicos eventuais podem desacelerar o consumo (ainda que alimento seja um dos itens com consumo constante) e afetar a organização; 3) o aumento de combustível, geralmente, gera distúrbios no mercado.

As medidas políticas também exercem influência direta nas ações da empresa, em especial as relacionadas a questões tributárias. Até dois anos atrás, por exemplo, todos os alimentos da cesta básica eram isentos de ICMS, no intuito de aumentar a arrecadação, os governos dos estados passaram a tributar esses produtos.

Como um mecanismo para dar suporte ao processo de formulação da sua estratégia, foi realizada uma análise SWOT, para identificação das suas forças, fraquezas, oportunidades e ameaças. A realização deste trabalho constitui-se num mecanismo para definição e/ou adequação de estratégias empresariais. Uma descrição da análise SWOT está abaixo discriminada:

Pontos Fortes: Estrutura Organizacional Enxuta, com Baixos Custos Operacionais; Diversa Linha de Produtos de Qualidade; Qualidade do seu quadro de pessoal; Serviços Diferenciados Adicionais; Informalidade; Excelente Rede de Relacionamentos.

Pontos Fracos: Falta de uma Programação Sistemática de Visitas In Loco; Fornecedores Distantes; Fraca Penetração em Redes de Supermercado.

Oportunidades: Tendência de Crescimento do Mercado Nordestino; Sistema de Incentivos Fiscais para o Nordeste; Desvalorização Cambial; Incentivo às Exportações; Aplicação de sistemas colaborativos.

Ameaças: Negociações Diretas; Fusão de Concorrentes; Variação da Política Tributária.

Uma análise do estudo do ambiente interno e externo da empresa e a da identificação das suas forças, fraquezas, ameaças e oportunidades, permite inferir que, tomando como referência a tipologia proposta por Mintzberg (2000), a estratégia utilizada 
tem sido a estratégia de diferenciação, em função das atitudes e movimentos dos seus concorrentes.

Considerando as características do atual ambiente de negócios e de gestão, caracterizado pela necessidade das organizações serem cada vez mais flexíveis e adaptáveis as implicações decorrentes da freqüência e velocidade das mudanças; as novas formas de gestão da cadeia de suprimento, caracterizada pelo interesse dos fabricantes passarem a ter preocupações direcionadas para a sua competência central, qual seja, o processo de fabricação, repassando para outros integrantes da cadeia produtiva algumas etapas do processo, em especial à parte de logística e distribuição. Isto fica evidenciado nas informações explicitadas neste trabalho e em especial junto à cadeia produtiva do setor de alimentos. Em função disto e dada às características da empresa pesquisada pode-se inferir que a empresa precisa redefinir a sua estratégia empresarial, como um mecanismo para adquirir as melhores condições de sobrevivência e desenvolvimento, passando de uma estratégia de diferenciação, baseada apenas na postura e atitude dos concorrentes, para uma estratégia de posicionamento, incorporando no processo de formulação da sua estratégia outras variáveis do seu ambiente e as suas próprias características.

Para viabilizar a mudança estratégica a ser adotada uma postura adequada seria a redefinição da sua forma de atuação passando a adotar e aplicar os princípios de redes, o que envolve a parceria, a associação, a complementaridade, etc. Este novo tipo de postura representa uma nova forma de atuação para as empresas dos vários segmentos e setores econômicos, incluindo o de fabricação e distribuição de alimentos. Os exemplos de novas formas de atuação empresariais neste setor têm sido: o broker e o operador logístico, os quais precisam der devidamente ajustados a contextos e características específicas.

\section{A Adaptação ao Modelo de Broker e Operador Logístico}

A tendência atual do setor de distribuição requer que o fluxo da cadeia de suprimentos seja comandado pela demanda do consumidor, e não mais ao contrário (da manufatura para a indústria, atacado/distribuidor, varejo e consumidor). Neste sentido, a empresa pesquisada está atenta e busca diferenciar-se dos demais representantes comerciais em sua forma de atuação, procurando incorporar algumas práticas dos novos formatos organizacionais para o setor de representação e distribuição de alimentos, quais sejam, o broker e o operador logístico. 
Em relação ao modelo de operador logístico, a empresa cuida da movimentação, transporte e processamento de pedidos do cliente. Porém, não controla estoques nem oferece armazenagem. A organização também trabalha para diversas empresas, incluindo empresas concorrentes, sem, no entanto, prejudicar os resultados de um fornecedor em detrimento de outro. Como seus clientes são distribuidores e atacadistas, são eles quem determina o seu mix de produtos.

Quanto ao modelo de broker, existem também algumas semelhanças, na medida em que, a empresa não compra as mercadorias, porém executa um eficiente trabalho de vendas. Sua remuneração é através de comissão sobre os pedidos faturados. Também oferece a linha completa das empresas que representa, tal qual o modelo de broker.

A partir destas constatações fica evidenciada uma tendência para a redefinição do seu modelo organizacional e, por conseguinte da sua forma de atuação. Neste sentido, a adoção de um novo modelo requer uma mudança de foco. A atuação como broker pressupõe a "pulverização" das vendas, eliminando-se a figura do distribuidor e do atacadista, uma vez que o broker efetua suas vendas diretamente ao varejo. Em alguns ramos de atividade, a atuação do broker é tão eficaz que a venda é feita diretamente ao consumidor final, o que significa uma revolução total na cadeia de suprimentos. No ramo alimentício, esse nível de eficiência ainda não é possível.

$\mathrm{Na}$ empresa pesquisada, os fornecedores estão localizados em sua maioria no Sul e Sudeste do país, utilizando transporte rodoviário, a mercadoria tarda em média seis dias para chegar até o seu destino final. Torna-se praticamente inviável a distribuição desses produtos, via broker, para um número muito grande de estabelecimentos, sem contar com a presença de um armazém. A presença de uma central de armazenagem para viabilizar sua atuação como broker é indispensável. Em resposta a essa necessidade, a empresa conta com uma distribuidora de alimentos pertencente ao seu grupo, com capacidade física para suprir a sua demanda. Dessa forma, surge como alternativa a formação de uma rede seguindo o seguinte modelo de cadeia de abastecimento:

Figura 3: Modelo organizacional para empresas envolvidas com a distribuição de alimentos

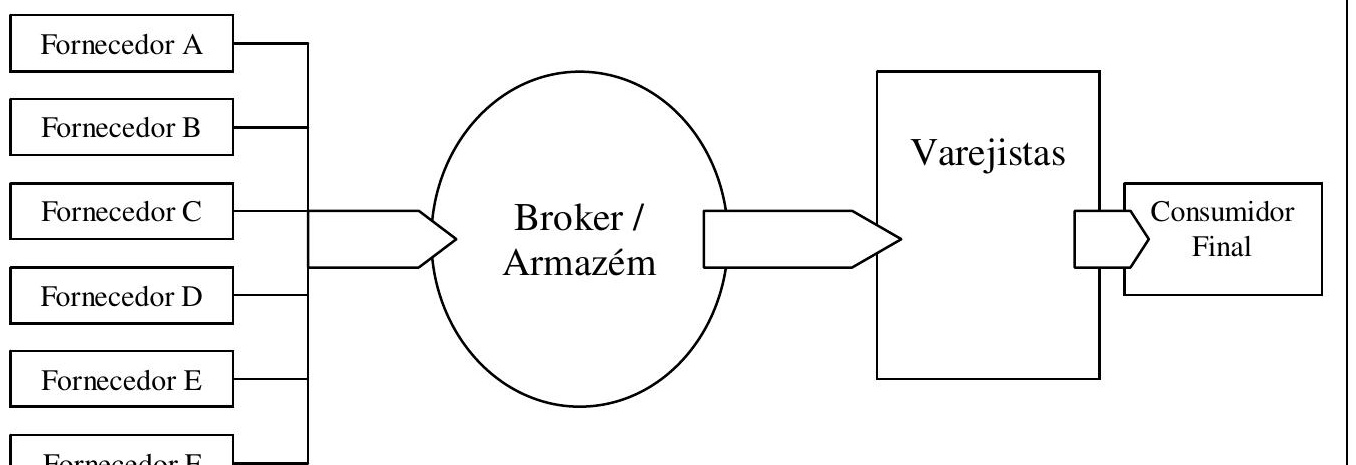




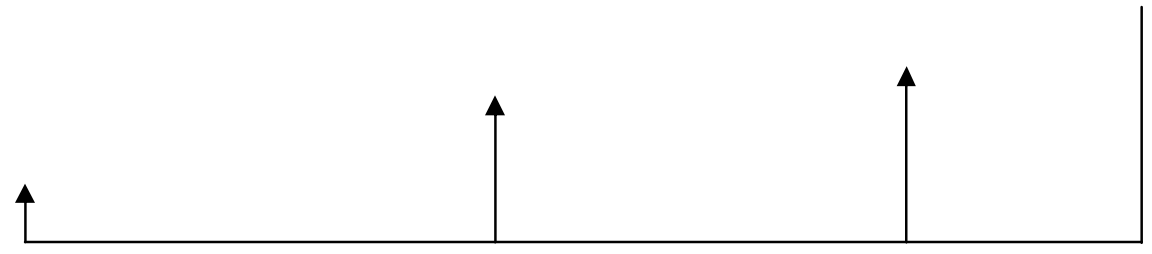

Fonte: proposição dos autores

O modelo proposto elimina duas figuras que antes figuravam na cadeia de abastecimento do setor de distribuição de alimentos: o Representante Comercial e o Atacadista/Distribuidor. Elimina também a bi-tributação, que ocorre através da venda ao Atacadista/Distribuidor e deste para o varejo. Neste sentido, o setor varejista ganha mais força e dinamismo, e a indústria mais penetração e competitividade. Consiste também em uma alternativa de reversão do quadro que se apresenta atualmente, onde a indústria está sendo esmagada pela pressão das grandes redes de varejo, e os varejistas de pequeno e médio porte estão sendo excluídos do mercado em virtude do seu baixo poder de compra e ineficiência administrativa.

A fusão das figuras do representante comercial e do distribuidor, antes meros intermediários no processo, significa o surgimento de um novo elemento capaz de agregar valor ao produto e, conseqüentemente, ao negócio de seus colaboradores. Essa integração da cadeia de abastecimentos é irreversível. Na chamada "era da colaboração”, os agentes passam a trabalhar mais perto uns dos outros, formando parcerias e trocando informações antes consideradas estratégicas. Todos buscam os melhores resultados em função de redução de custos, de desperdícios e de agregação de valor ao consumidor final.

Entende-se que os princípios de rede estão em constante mutação, e novos modelos surgem a todo instante. Nesse contexto, a adoção desses princípios antes da concorrência significa obtenção de real vantagem competitiva. Por outro lado, a adoção dessa estratégia enquadra-se no que Porter (1986) chama de "movimentos ameaçadores". Segundo o autor, na maioria dos mercados, uma característica central da concorrência é que as empresas são mutuamente dependentes: elas sentem os efeitos dos movimentos das outras e tendem reagir a eles. Muitos dos movimentos que melhoram significativamente a posição de uma empresa ameaçam na verdade os concorrentes. 
Uma vez consolidado o modelo proposto, a primeira conseqüência que se pode prever será um amplo processo de fidelização dos clientes, o que será obtido, na medida em que, ocorrerá: redução no custo dos produtos; novos posicionamentos mercadológicos, melhores e maiores ofertas de serviços disponibilizados para os seus clientes. Tendo alcançado maior fidelidade dos clientes, a estratégia inicial pode ser expandida, garantindo ainda mais a eficácia do modelo e proporcionando mais competitividade ao pequeno e médio varejista, através da criação de uma rede de lojas.

$\mathrm{Na}$ pesquisa realizada constatou-se que a entrada dos grandes supermercados afetou o varejo independente no que se refere a custos, mix competitivo de produtos e capacidade de atrair o consumidor. Foram percebidas cinco áreas críticas que poderiam ser resolvidas por meio da formação de uma rede são elas:

- Poder de compra - o varejo independente não tem um volume de compras que possibilite negociações de preços nos mesmos níveis das grandes redes, o que o torna menos competitivo;

- Comunicação e Marketing - são inviáveis o uso de mídia televisiva e/ou outros instrumentos de alto impacto;

- Capital Competitivo - o financiamento para modernização, ou mesmo capital de giro, é inviável no sistema financeiro tradicional, pois o spread - margem acrescentada aos juros em função do nível de risco da operação - utilizado para empresas de pequeno/médio porte, pode comprometer a lucratividade e, portanto, o próprio negócio;

- Tecnologia de Gestão - o pequeno e médio varejo dificilmente têm acesso às novas tendências e tecnologias existentes no mercado, e dificilmente terão tempo para acompanhar a sua evolução e adquirir o conhecimento necessário para avaliar a adequação do sistema ao seu negócio;

- Logística - área vital em qualquer negócio; se for bem administrada, ocasionará grandes diminuições nos custos de uma empresa e acrescentará agilidade em suas operações.

Para a implementação da nova estrutura e modelo organizacional baseado na forma de atuação, alguns pré-requisitos tornam-se indispensáveis e isto precisa ser devidamente estabelecido num projeto específico, o qual dentre outros aspectos deve abordar: 
- A definição de um tamanho mínimo e máximo para a área de vendas da loja, bem como o número mínimo e máximo de check-outs;

- Prever o desenvolvimento de unidades no conceito de "lojas de vizinhança", o que requer a implantação de seções de padaria, hortifrutigranjeiros, açougue, frios, congelados e mercearia. Para evitar a concorrência entre os filiados, não será permitida a presença de mais de uma loja da rede dentro de uma mesma região;

- Definição da forma de remuneração do broker criado (o administrador da rede). Neste sentido, cada estabelecimento filiado pagaria mensalmente uma certa quantia, a título de taxa de administração, o que cobriria todos os serviços prestados;

- Criação de mecanismos para fortalecer e consolidar a imagem da marca, buscando a padronização visual das lojas.

Diante de um cenário varejista cada vez mais competitivo e concentrado em grandes bandeiras, a rede funcionaria como retaguarda para as lojas, oferecendo as melhores opções de abastecimento de produtos, planos de marketing, vendas e apoio à gestão das lojas. Atuando com maior eficiência em conjunto, os varejistas terão a perspectiva de aumentar suas vendas e, conseqüentemente, sua lucratividade.

Para a empresa pesquisada, o conjunto de estratégias proposto consiste na base para a conquista e domínio do mercado onde está inserida, revolucionando as formas de distribuição do setor alimentício local. Também consiste o caminho evolutivo natural que a organização deve percorrer para manter-se no cenário mercadológico que ora se apresenta. A elaboração dessas duas abordagens estratégicas tem por finalidade comum aumentar os diferencias competitivos da organização e elevá-la a um desempenho superior. Tais ações darão à organização uma excelente vantagem competitiva, pois será uma das primeiras empresas ("first mover") a oferecer esse tipo de serviço no segmento onde atua.

\section{Considerações Finais}

Uma série de fatores, dentre eles a globalização, o avanço tecnológico e as mudanças comportamentais, forçaram as empresas a otimizarem seus desempenhos, diminuindo seus custos e o ciclo de vida dos seus produtos e serviços, e aumentarem sua produtividade. Esse processo desencadeou o surgimento de um modelo de organizações, onde um conjunto de empresas independentes passa a manter relações dinâmicas e específicas, denominado genericamente como "organizações em rede”. Pequenas e Médias 
Empresas têm se beneficiado desse modelo em diversos setores, obtendo vantagens competitivas significativas. Porém, não se tem conhecimento da aplicação desses princípios entre as empresas envolvidas no processo de distribuição de alimentos na região. $\mathrm{O}$ setor de distribuição alimentícia apresenta os seguintes agentes: o representante comercial, o distribuidor, o atacadista e o varejista.

A adoção dos princípios de redes fez surgir nesse cenário duas novas figuras: o broker e o operador logístico, representando uma tendência evolutiva para os agentes do setor de distribuição. Essas duas figuras representam, para a indústria, uma forma de aumentar sua participação nos pequenos pontos de vendas e, para os clientes, uma maneira de receber atendimento personalizado e preços competitivos.

O presente trabalho apresentou uma proposta de tornar uma empresa do setor de representação de alimentos numa agência que agregaria características de broker e de operador logístico. O modelo proposto prevê que a atuação como broker/operador logístico pressupõe a pulverização das vendas diretamente da indústria ao varejo, eliminando-se a figura do distribuidor, do atacadista e do próprio representante comercial. Para que o processo de distribuição seja viabilizado, requer-se a presença de um armazém. Em resposta a essa necessidade, a empresa poderia incorporar e/ou criar uma outra empresa, cuja atuação seria concentrada na armazenagem e distribuidora de alimentos, adotando o novo modelo de negócios e as estratégias aqui apresentadas.

A adoção do modelo aqui proposto criaria melhores condições para que o intermediário pudesse agregar valor ao negócio. Isto ocorre na medida em que, ocorre a integração da cadeia de suprimento, o que implica uma empresa ser mais ágil e rápida, capaz de reformular o seu modelo de negócios e, chegar ao mercado antes que seus concorrentes. O conjunto de estratégias apresentado visa proporcionar vantagens consideráveis, tanto na redução de custos na cadeia de abastecimento quanto em eficiência, agilidade, e otimização de recursos para fabricantes, varejistas e consumidores.

\section{BIBLIOGRAFIA}

AFRICK, J. M., CALKINS, C. S. Does Asset Ownership mean better Service? In: Transportation and Distribution, v.35, n.5, p.49-61, mai.1994. 
AMATO NETO, J. Redes de cooperação produtiva e clusters regionais: oportunidades para as pequenas e médias empresas. São Paulo: Atlas, 2000.

CÂNDIDO, G. A; ABREU, A, F. Os conceitos de redes e as relações interorganizacionais: um estudo exploratório. In: ENCONTRO ANUAL DA ANPAD, 24, 2000, Florianópolis. Anais... Florianópolis: ANPAD, 2000. 1 CD.

CÂNDIDO, G. A; ABREU, A, F. Aglomerados industriais de pequenas e médias empresas como mecanismo para promoção de desenvolvimento regional. Read, Porto Alegre, v. 6, n. 6, dez. 2000. Disponível em <http://read.adm.ufrgs.br/read18/read18.htm>. acesso em 19/12/2002

CÂNDIDO, G. A; ABREU, A, F; GOEDERT, A. R. et al. Metodologia para formação de redes de inovação entre pequenas e médias empresas. In: SIMPÓSIO DE GESTÃO DA INOVAÇÃO TECNOLÓGICA, 21., 2000, São Paulo. Anais... São Paulo: USP, 2000. 1CD.

CÂNDIDO, G. A. Fatores Críticos de Sucesso no Processo de Formação, Desenvolvimento e Manutenção de Redes Interorganizacionais do tipo Agrupamentos Industriais PME's: um estudo comparativo de experiências brasileiras, 356 p. Tese (Doutorado em Engenharia de Produção). Programa de Pósgraduação em Engenharia de Produção. Universidade Federal de Santa Catarina, 2001

COUTINHO, L.; FERRAZ, J. C. Estudo da competitividade da indústria brasileira. Campinas - SP: Papirus, 1994.

FERREIRA, N. R., AMATO NETO, J., PIKMAN, M., Redes de Empresas e o Desenvolvimento da Tecnologia da Informação. In: Anais do ENEGEP98. 1 CD. Niterói-RJ, 1998.

FERREIRA, V. G. Aliança estratégica: atacados de entrega formam redes de varejos que garantem clientes fiéis e a sobrevivência dos pequenos e médios supermercados. In: Distribuição, Ano X, no 113, abril/2002. p. 184-186.

GIL, A C., Métodos e técnicas de pesquisa social. São Paulo: Atlas, 1999

KANTER, R. M. O futuro depende dos relacionamentos. HSM Management, São Paulo, v. 4, n. 2, p. 112-118, maio-junho 2000.

LA CONDE, B. É tempo de integração. HSM Management, São Paulo, Ano 4, n. 21, p. 56-62, julho-ago. 2000. 
MINTZBERG, H. A criação artesanal da estratégia. In: MONTGOMERY, CYNTHIA A.; PORTER, M. E. Estratégia: a busca da vantagem competitiva. Rio de Janeiro: Campus, 1998.

NADLER, D., TUSHMAN, M. L. Projeto de organizações com boa adequação: uma moldura para compreender as novas arquiteturas. In: NADLER, D., GERSTEIN, M. S., SHAW, R. Arquitetura Organizacional - a chave para a mudança organizacional. Rio de Janeiro: Campus, 1994. p. 29-47.

POIRIER, C. C., REITER, S. E., Otimizando sua rede de negócios: como desenvolver uma poderosa rede entre fornecedores, fabricantes, distribuidores e varejistas. São Paulo: Futura, 1997.

PORTER, M. E. Estratégia competitiva: Técnicas para análise de indústrias e da concorrência. Rio de Janeiro: Campus, 1986.

PROFFITT, M. Distribuição multimodal. HSM Management, São Paulo, Ano 1, n. 5, p.32-36, novembro-dez. 1997.

RIVERAS, I., MATHIAS, J. Fartura como nunca se viu: os potenciais do mercado atraem gigantes internacionais.- Atlas do Mercado Brasileiro, São Paulo, Ano 1, n.1, p. 240-242, dezembro 1998. Gazeta Mercantil.

SALGUEIRO, S., SANTOS V. Em franca expansão: serviços de broker e operador logístico ganham espaço entre atacadistas e distribuidores. In: Distribuição, Ano X, $n^{\circ} 113$, abril/2002.p. 164-182.

YIN, R. K., Estudo de caso: planejamento e métodos. Porto Alegre: Bookman, 2001. 